\begin{tabular}{|c|c|c|}
\hline $\begin{array}{l}\text { ITC 1/47 } \\
\text { Journal of Information Technology }\end{array}$ & \multicolumn{2}{|c|}{$\begin{array}{c}\text { Controlling Hyperchaotic Finance System with Combining } \\
\text { Passive and Feedback Controllers }\end{array}$} \\
\hline $\begin{array}{l}\text { Vol. } 47 / \text { No. } 1 / 2018 \\
\text { pp. } 45-55\end{array}$ & Received 2017/03/28 & Accepted after revision 2018/01/09 \\
\hline $\begin{array}{l}\text { DOI 10.5755/j01.itc.47.1.16898 } \\
\text { ๑ Kaunas University of Technology }\end{array}$ & \multicolumn{2}{|c|}{ crossef http://dx.doi.org/10.5755/j01.itc.47.1.16898 } \\
\hline
\end{tabular}

\title{
Controlling Hyperchaotic Finance System with Combining Passive and Feedback Controllers
}

\section{Uğur Erkin Kocamaz}

Department of Computer Technologies, Vocational School of Karacabey, Uludağ University, 16700 Karacabey, Bursa, Turkey; phone: +90 224294 2662; fax:+90 224676 5562; e-mail: ugurkocamaz@gmail.com Institute of Natural Sciences, Sakarya University, Serdivan 54187, Sakarya, Turkey

\section{Alper Göksu}

Department of Industrial Engineering, Faculty of Engineering, Sakarya University, 54187 Serdivan, Sakarya, Turkey; phone: +90 264295 5492; fax: +90 264295 5601; e-mail: agoksu@sakarya.edu.tr

\section{Yllmaz Uyaroğlu}

Department of Electrical \& Electronics Engineering, Faculty of Engineering, Sakarya University, 54187 Serdivan, Sakarya, Turkey; phone: +90 264295 5814; fax: +90 264 295 5601; e-mail: uyaroglu@sakarya.edu.tr

\section{Harun Taşkin}

Department of Industrial Engineering, Faculty of Engineering, Sakarya University, 54187 Serdivan, Sakarya, Turkey; phone: +90 264 295 5659; fax: +90 264295 5601; e-mail: taskin@sakarya.edu.tr

Corresponding author: ugurkocamaz@gmail.com

In this paper, a novel control method that combines passive, linear feedback, and dislocated feedback control methods is proposed and applied to the control of the four-dimensional hyperchaotic finance system which has been introduced and controlled with the linear feedback and speed feedback control methods by Yu, Cai, and $\mathrm{Li}$ (2012). The stability of the hyperchaotic finance system at its equilibrium points is ensured on the basis of a Lyapunov function. Computer simulations are used for verifying all the theoretical analyses visually. In the simulations, the proposed control method is also compared with the speed feedback and linear feedback control methods to observe its effectiveness. Finally, the comparative findings are discussed.

KEYWORDS: Hyperchaotic finance system, passive control, speed feedback control, linear feedback control, dislocated feedback control, chaos control. 


\section{Introduction}

This paper investigates the control of a hyperchaotic finance system which was proposed by Yu et al. [46]. Almost all financial systems have nonlinear factors, multiplicity and ambiguity in their inward structure. They may cause undesired chaotic trajectories which had better be eliminated. Therefore, it has become important to inquire the control of chaos in the financial systems. Since the pioneer study of Ott et al. in 1990 [29], several effective methods for the control of chaotic systems have been proposed. The chaos control approaches include linear feedback control $[13,15,16,18,22,24,41,44,47]$, nonlinear feedback control [7], time-delayed feedback control [34], adaptive control [2, 40], sliding mode control [22,12], passive control [ $8,22,28,33,45]$, backstepping design [12, 32], and intelligent control [20] methods. Among them, the linear feedback control has been widely used due to its simplicity of implementation. It stabilizes the chaotic system with the negative feedback gains of related state variables. In recent years, it has been applied for the control of Lorenz [47], Chua [18], Rössler [16], Chen [13], Lü [24], Liu [41], four-dimensional Rabinovich [22], and many other chaotic systems $[15,44]$. If another feedback state variable gain is used, then it is named as dislocated feedback control method. The control of Lorenz [36], Liu [51], and Lü [31] chaotic systems to their equilibrium points is achieved with the dislocated feedback control. The speed feedback control method uses the derivative of independent variable by multiplying with a coefficient as a feedback gain. The Lorenz [36], Liu [51], Lü [31], unified [37], Rössler [37], and Tigan [9] chaotic systems are successfully controlled with the speed feedback control method. Passive control, the other significant chaos control method, has been applied for the control of Lorenz [45], Chen [33], unified [8], four-dimensional Rabinovich [22], and some other chaotic systems [28]. The goal of the passivity theory is to keep a system asymptotically stable. It is done by a controller which makes the closed loop system passive upon the specificities of the system. The methodology of passivity can be accessed in a number of papers $[8,28,33,45]$.

In 2001, the first chaotic finance system was introduced $[25,26]$. Then, some new chaotic finance systems were proposed [3, 4, 35]. Afterwards, a hyperchaotic finance system was shown [10]. In 2012, Yu et al. presented a new hyperchaotic finance attractor from the first chaotic finance system [46]. Several control methods were used for the control of chaos and hyperchaos in finance systems. Linear feedback controllers [5, 42], speed feedback controllers [5, 42], adaptive controllers [5, 35], selection of gain matrix controllers [42], revision of gain matrix controllers [42], positive feedback gain matrix [49], time-delayed feedback controllers [6, 43, 48], nonlinear feedback controllers [1], linear controllers [23], a passive controller [11], $H_{\infty}$ controllers [50], active controllers [30], and neural controllers [21] were assigned for the control of chaotic finance equations. The control of the former hyperchaotic finance system was reported with the speed feedback [10], linear feedback [39], time-delayed feedback [14], and sliding mode [38] control methods. The control of the latter hyperchaotic finance system was achieved with the speed feedback [46], linear feedback [46], nonlinear recursive backstepping [17], and sliding mode [17] controllers. According to the literature review, although the synchronization of chaotic finance system is applied with the passive control method [19], there has not been any published papers which have specifically exploited the control of a hyperchaotic finance system by using a passivity based control method.

In this paper, a further approach on the control of the new hyperchaotic finance system is analysed. The remainder of this paper is organized in the following order. In Section 2, a brief representation of the related chaotic and hyperchaotic finance systems is given. In Section 3, in order to achieve the control of new hyperchaotic finance system, the hybrid controllers including passive controllers, a linear feedback controller, and a dislocated feedback controller are employed. In Section 4, simulation results are obtained numerically and presented graphically to confirm the efficiency of the proposed control method by comparing with the speed feedback and linear feedback control results. Finally, the paper is concluded in Section 5.

\section{The Hyperchaotic Finance System}

The following differential equations define the three-dimensional chaotic finance system: 
$\dot{x}=z+(y-a) x$,

$\dot{y}=1-b y-x^{2}$,

$\dot{z}=-x-c z$.

In system (1), the state variables $x, y, z$ represent the interest rate, investment demand, price exponent; the positive real constants $a, b, c$ represent saving amount, per-investment cost, elasticity of demands of commercials, respectively [25, 26]. When the parameter values are $a=0.9, b=0.2$, and $c=1.2$, the nonlinear finance system (1) displays chaotic motions [42]. Under the initial values $x(0)=1, y(0)=2$, and $z(0)=-0.5$, the three-dimensional phase plane of the chaotic finance system is shown by using MATLAB's ode45 function in Fig. 1.

\section{Figure 1}

3D phase plane of the chaotic finance system

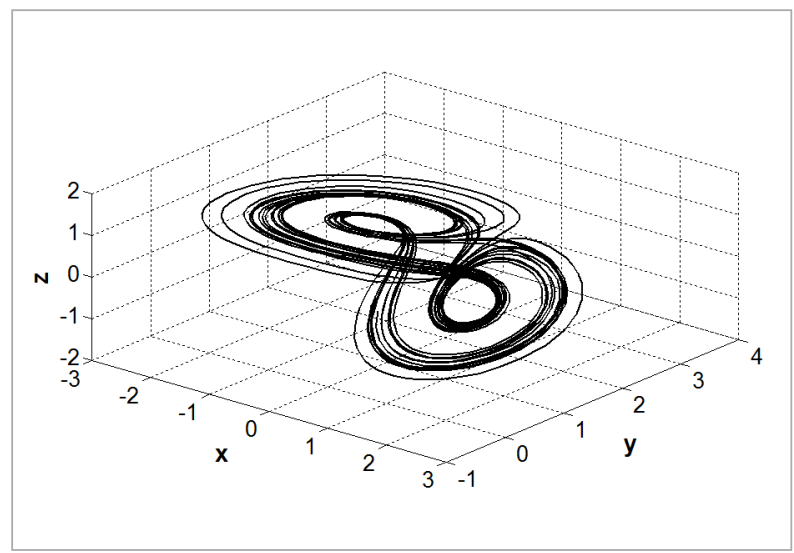

The following first-order differential equations define the new four-dimensional hyperchaotic finance system:

$\dot{x}=z+(y-a) x+w$,

$\dot{y}=1-b y-x^{2}$,

$\dot{z}=-x-c z$,

$\dot{w}=-d x y-k w$,

where $w$ is the new state variable that represents average profit margin, and $d, k$ are new positive real constants [46]. The hyperchaotic varies of system (2) are analysed with demonstrating the bifurcation diagrams versus parameters $c$ and $k$ [46]. It displays hyperchaotic behaviour for the parameter values $a=0.9, b=0.2, c=1.5, d=0.2$, and $k=0.17$ [46]. Under the initial values $x(0)=1, y(0)=2, z(0)=0.5$, and $w(0)=0.5$, the time series and three-dimensional phase planes of the hyperchaotic finance system are shown by using MATLAB's ode45 function in Fig. 2 and Fig. 3, respectively.

Figure 2

Time series of hyperchaotic finance system for (a) $x$ signals, (b) $y$ signals, (c) $z$ signals, and (d) $w$ signals
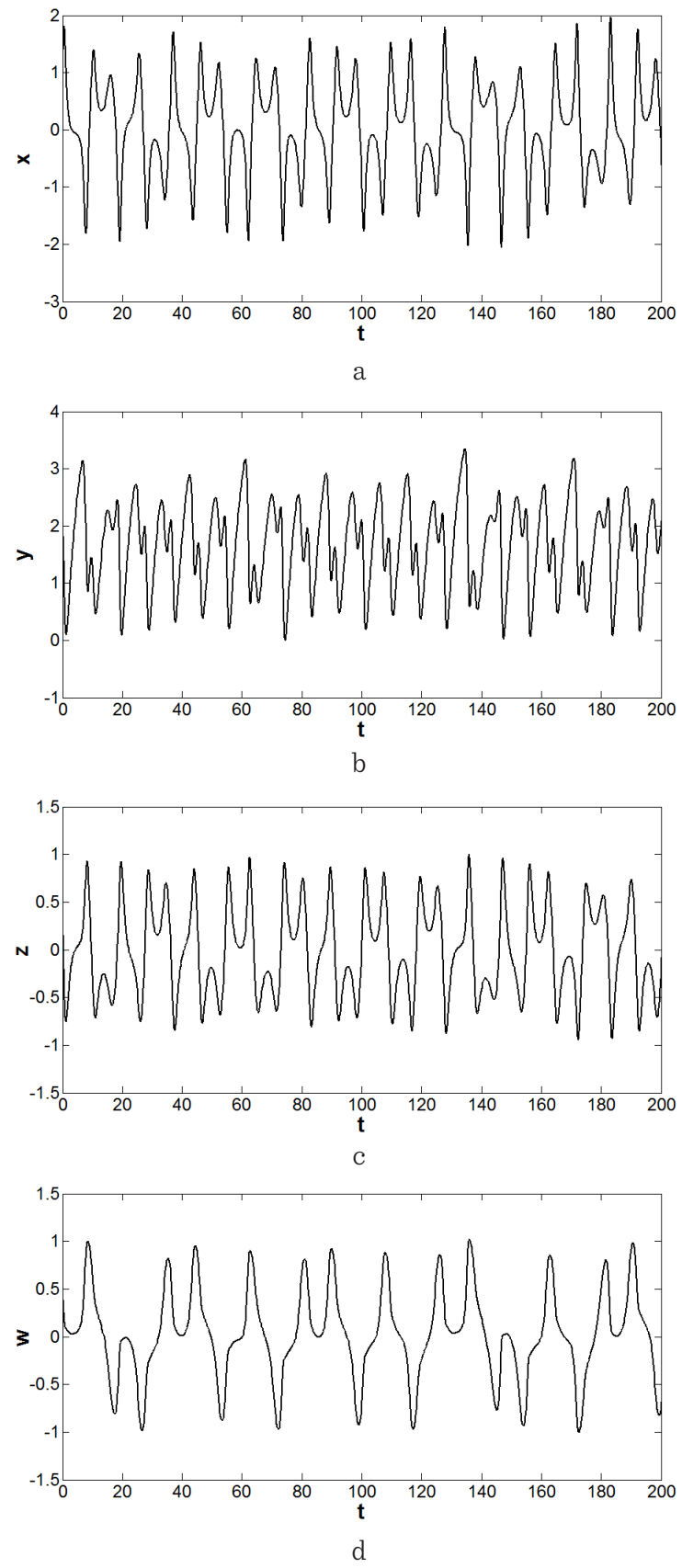


\section{Figure 3}

3D phase planes of hyperchaotic finance system for (a) $x-y-z$ phase plane, (b) $x-y-w$ phase plane, (c) $x-z-w$ phase plane, and (d) $y-z-w$ phase plane

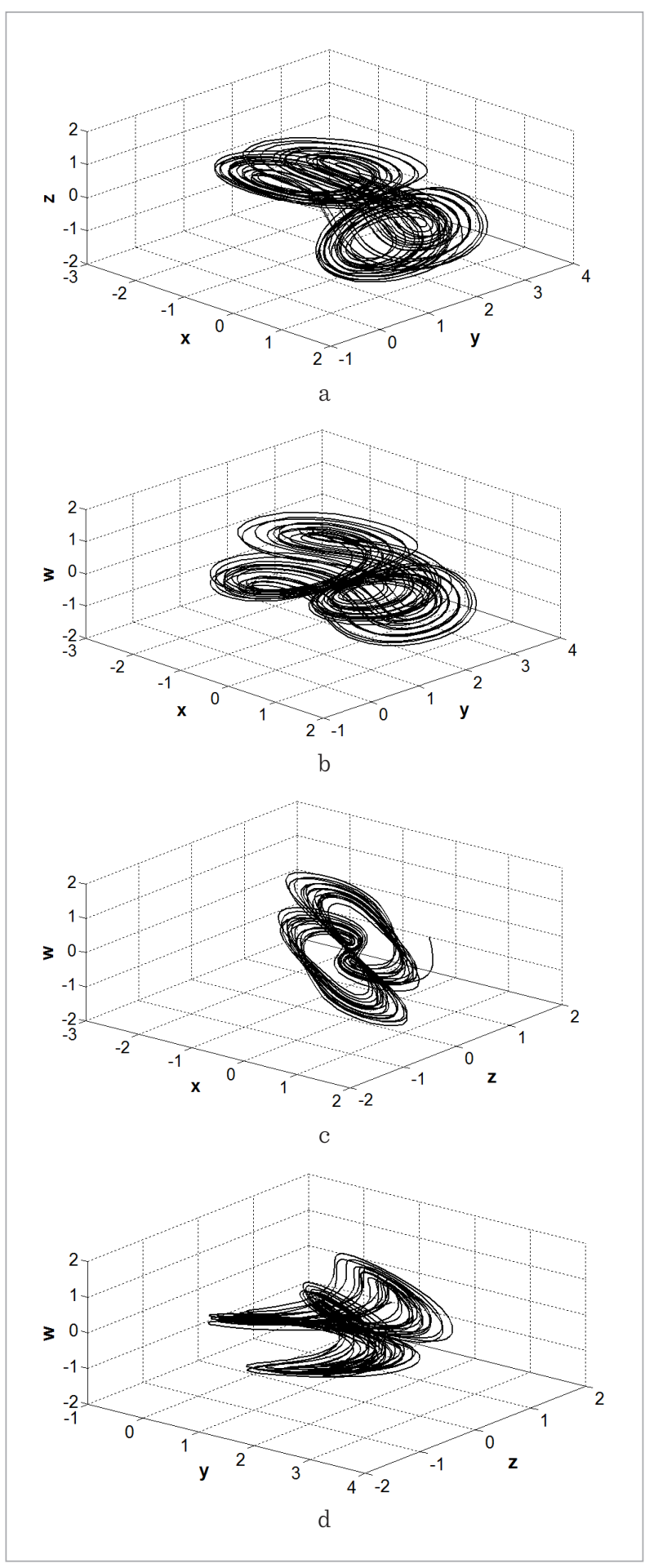

The system (2) has three equilibrium points: $E_{1}(0,1 / b$, $0,0), E_{2}(-\theta,(k+a c k) /(k-d), \theta / c,-\theta d(1+a c) /(c d-c k))$, and $E_{3}(\theta,(k+a c k) /(k-d),-\theta / c, \theta d(1+a c) /(c d-c k))$ where $\theta=\sqrt{(b k+a b c k) /(c d-c k)+1}$. According to the above-given parameter values, the equilibrium points of hyperchaotic finance system are calculated as: $E_{1}(0$, $5,0,0), E_{2}(1.66,-8.87,-1.11,17.4)$, and $E_{3}(-1.66,-8.87$, $1.11,-17.4)$.

\section{The Control of Hyperchaotic Finance System}

In this section, the control of new hyperchaotic finance system is applied with a passivity based feedback control method. In addition, the controlled hyperchaotic finance system via speed feedback and linear feedback control methods are described.

\subsection{The Passive Feedback Control}

For the control of hyperchaotic finance system to its equilibrium points, $u_{1}, u_{2}, u_{3}$, and $u_{4}$ controllers are added to the system (2). Then, the controlled system becomes

$$
\begin{aligned}
& \dot{x}=z+(y-a) x+w+u_{1}, \\
& \dot{y}=1-b y-x^{2}+u_{2}, \\
& \dot{z}=-x-c z+u_{3}, \\
& \dot{w}=-d x y-k w+u_{4} .
\end{aligned}
$$

An equilibrium point of the system can be defined as $(\bar{x}, \bar{y}, \bar{z}, \bar{w})$, then the trajectory error states are determined as $e_{1}=x-\bar{x}, e_{2}=y-\bar{y}, e_{3}=z-\bar{z}$, and $e_{4}=w-\bar{w}$. Thus, the state variables are $x=e_{1}+\bar{x}$, $y=e_{2}+\bar{y}, z=e_{3}+\bar{z}$, and $w=e_{4}+\bar{w}$. The error state dynamic equations of system (3) can be denoted as

$$
\begin{aligned}
& \left.\dot{e}_{1}=\left(e_{3}+\bar{z}\right)+\left(e_{2}+\bar{y}\right)-a\right)\left(e_{1}+\bar{x}\right)+\left(e_{4}+\bar{w}\right)+u_{1}, \\
& \dot{e}_{2}=1-b\left(e_{2}+\bar{y}\right)-\left(e_{1}+\bar{x}\right)^{2}+u_{2}, \\
& \dot{e}_{3}=-\left(e_{1}+\bar{x}\right)-c\left(e_{3}+\bar{z}\right)+u_{3}, \\
& \dot{e}_{4}=-d\left(e_{1}+\bar{x}\right)\left(e_{2}+\bar{y}\right)-k\left(e_{4}+\bar{w}\right)+u_{4} .
\end{aligned}
$$

Then, the error dynamics in system (4) become

$$
\begin{aligned}
& \dot{e}_{1}=(\bar{y}-a) e_{1}+\bar{x} e_{2}+e_{3}+e_{4}+e_{1} e_{2}-a \bar{x}+\bar{z}+\bar{w}+\overline{x y}+u_{1} \\
& \dot{e}_{2}=-e_{1}^{2}-2 \bar{x} e_{1}-b e_{2}-\bar{x}^{2}-b \bar{y}+1+u_{2} \\
& \dot{e}_{3}=-e_{1}-c e_{3}-\bar{x}-c \bar{z}+u_{3} \\
& \dot{e}_{4}=-d \bar{y} e_{1}-d \bar{x} e_{2}-k e_{4}-d e_{1} e_{2}-k \bar{w}-d \overline{x y}+u_{4} .
\end{aligned}
$$


Because of $-a \bar{x}+\bar{z}+\bar{w}+\overline{x y}=0, \quad-\bar{x}^{2}-b \bar{y}+1=0$, $-\bar{x}-c \bar{z}=0$, and $-k \bar{w}-d \overline{x y}=0$, they do not affect the error dynamics. Thus, system (5) can be simplified as

$$
\begin{aligned}
& \dot{e}_{1}=(\bar{y}-a) e_{1}+\bar{x} e_{2}+e_{3}+e_{4}+e_{1} e_{2}+u_{1}, \\
& \dot{e}_{2}=-e_{1}^{2}-2 \bar{x} e_{1}-b e_{2}+u_{2}, \\
& \dot{e}_{3}=-e_{1}-c e_{3}+u_{3}, \\
& \dot{e}_{4}=-d \bar{y} e_{1}-d \bar{x} e_{2}-k e_{4}-d e_{1} e_{2}+u_{4} .
\end{aligned}
$$

The state variable $e_{1}$ is considered as the output of the system by taking $u_{2}=0, u_{3}=0, u_{4}=0 . Z_{1}=e_{2}, Z_{2}=e_{3}, Z_{2}=$ $e_{4}, Y=e_{1}$, and $Z=\left[Z_{1} Z_{2} Z_{3}\right]$ are assumed. Then, system (6) can be rewritten as

$$
\begin{aligned}
& \dot{Z}_{1}=-Y^{2}-2 \bar{x} Y-b Z_{1}, \\
& \dot{Z}_{2}=-Y-c Z_{2}, \\
& \dot{Z}_{3}=-d \bar{y} Y-d Y Z_{1}-d \bar{x} Z_{1}-k Z_{3}, \\
& \dot{Y}=(\bar{y}-a) Y+Y Z_{1}+\bar{x} Z_{1}+Z_{2}+Z_{3}+u_{1} .
\end{aligned}
$$

The passivity definition has the following generalized form [45]:

$$
\begin{aligned}
& \dot{Z}=f_{0}(Z)+p(Z, Y) Y, \\
& \dot{Y}=b(Z, Y)+a(Z, Y) u,
\end{aligned}
$$

where system ( 7 ) can be written in the normal form of system (8) as follows:

$$
\begin{aligned}
& f_{0}(Z)=\left[\begin{array}{c}
-b Z_{1} \\
-c Z_{2} \\
-d \bar{x} Z_{1}-k Z_{3}
\end{array}\right], \\
& p(Z, Y)=\left[\begin{array}{c}
-Y-2 \bar{x} \\
-1 \\
-d \bar{y}-d Z_{1}
\end{array}\right], \\
& b(Z, Y)=(\bar{y}-a) Y+Y Z_{1}+\bar{x} Z_{1}+Z_{2}+Z_{3}, \\
& a(Z, Y)=1 .
\end{aligned}
$$

Let a storage function be selected as

$$
V(Z, Y)=W(Z)+\frac{1}{2} Y^{2},
$$

where

$$
W(Z)=\frac{1}{2}\left(Z_{1}^{2}+Z_{2}^{2}+Z_{3}^{2}\right)
$$

is the Lyapunov function of $f_{0}(Z)$, and $W(0)=0$. The zero dynamics of system ( 7 ) describe the internal dynamics which are consistent with the external constraint $\dot{Z}=f_{0}(Z)$. It implies

$$
\begin{aligned}
\frac{d}{d t} V(Z, Y)= & \frac{\partial W(Z)}{\partial Z} \dot{Z}+Y \dot{Y} \\
= & \frac{\partial W(Z)}{\partial Z} f_{0}(Z)+\frac{\partial W(Z)}{\partial Z} p(Z, Y) Y \\
& +b(Z, Y) Y+a(Z, Y) Y u
\end{aligned}
$$

The error system can be obtained with a minimum phase

$$
\frac{d}{d t} W(Z) f_{0}(Z) \leq 0 .
$$

Then, Equation (15) becomes

$$
\frac{d}{d t} V(Z, Y) \leq \frac{\partial W(Z)}{\partial Z} p(Z, Y) Y+b(Z, Y) Y+a(Z, Y) Y u .
$$

The zero dynamics of system (8) describe the internal dynamics that is relevant with the external constraint $Y=0$, i.e., $\dot{Z}=f_{0}(Z) \cdot \dot{W}(Z)$ according to Equation (9) is

$$
\begin{aligned}
\dot{W}(Z) & =\frac{\partial W(Z)}{\partial Z} f_{0}(Z)=\left[\begin{array}{lll}
Z_{1} & Z_{2} & Z_{3}
\end{array}\right]\left[\begin{array}{c}
-b Z_{1} \\
-c Z_{2} \\
-d \bar{x} Z_{1}-k Z_{3}
\end{array}\right] \\
& =-b Z_{1}^{2}-c Z_{2}^{2}-d \bar{x} Z_{1} Z_{3}-k Z_{3}^{2}
\end{aligned}
$$

which is not exactly negative definite. This implies that $f_{0}(Z)$ is not globally asymptotically stable. Thus, the classical passive control method does not ensure the control of system (6). For a solution, control signal $u_{4}$ is assumed as a dislocated feedback controller and linear feedback gains are also added to the states for better control performance. They are taken as

$$
\begin{aligned}
& u_{2}=-k_{1} e_{2}, \\
& u_{3}=-k_{1} e_{3}, \\
& u_{4}=d \bar{x} e_{2}-k_{1} e_{4},
\end{aligned}
$$

where $k_{1}$ is a positive real constant. Now, system (6) becomes

$$
\begin{aligned}
& \dot{e}_{1}=(\bar{y}-a) e_{1}+\bar{x} e_{2}+e_{3}+e_{4}+e_{1} e_{2}+u_{1}, \\
& \dot{e}_{2}=-e_{1}^{2}-2 \bar{x} e_{1}-\left(b+k_{1}\right) e_{2}, \\
& \dot{e}_{3}=-e_{1}-\left(c+k_{1}\right) e_{3}, \\
& \dot{e}_{4}=-d \bar{y} e_{1}-\left(k+k_{1}\right) e_{4}-d e_{1} e_{2} .
\end{aligned}
$$


The state variable $e_{1}$ is again considered as the output of the system. $Z_{1}=e_{2}, Z_{2}=e_{3}, Z_{2}=e_{4}, Y=e_{1}$, and $Z=\left[Z_{1} Z_{2}\right.$ $\left.Z_{3}\right]$ are assumed. Then, system (20) can be rewritten as

$$
\begin{aligned}
& \dot{Z}_{1}=-Y^{2}-2 \bar{x} Y-\left(b+k_{1}\right) Z_{1}, \\
& \dot{Z}_{2}=-Y-\left(c+k_{1}\right) Z_{2}, \\
& \dot{Z}_{3}=-d \bar{y} Y-d Y Z_{1}-\left(k+k_{1}\right) Z_{3}, \\
& \dot{Y}=(\bar{y}-a) Y+Y Z_{1}+\bar{x} Z_{1}+Z_{2}+Z_{3}+u_{1} .
\end{aligned}
$$

System (21) can be written in the normal form of system (8) as follows:

$$
f_{0}(Z)=\left[\begin{array}{l}
-\left(b+k_{1}\right) Z_{1} \\
-\left(c+k_{1}\right) Z_{2} \\
-\left(k+k_{1}\right) Z_{3}
\end{array}\right]
$$

$$
p(Z, Y)=\left[\begin{array}{c}
-Y-2 \bar{x} \\
-1 \\
-d \bar{y}-d Z_{1}
\end{array}\right],
$$

$b(Z, Y)=(\bar{y}-a) Y+Y Z_{1}+\bar{x} Z_{1}+Z_{2}+Z_{3}$,

$a(Z, Y)=1$

If the same storage and Lyapunov functions are taken as in Equations (13) and (14), then the derivative of $W(Z)$, according to Equation (22), becomes

$$
\begin{aligned}
\dot{W}(Z) & =\left[\begin{array}{lll}
Z_{1} & Z_{2} & Z_{3}
\end{array}\right]\left[\begin{array}{l}
-\left(b+k_{1}\right) Z_{1} \\
-\left(c+k_{1}\right) Z_{2} \\
-\left(k+k_{1}\right) Z_{3}
\end{array}\right] \\
= & -\left(b+k_{1}\right) Z_{1}^{2}-\left(c+k_{1}\right) Z_{2}^{2}-\left(k+k_{1}\right) Z_{3}^{2},
\end{aligned}
$$

which is negative definite. This implies that $f_{0}(Z)$ is globally asymptotically stable. Thus, the zero dynamics of the controlled hyperchaotic finance system (21) is stable with the Lyapunov's method and it is a minimum phase system.

According to the passive control method, the controlled system (21) will be equivalent to a passive system and globally asymptotically stabilized at its zero equilibrium if the state controller is considered as in the following equation [27]:

$$
u=a(Z, Y)^{-1}\left\lceil-b(Z, Y)-\left(\frac{\partial W(Z)}{\partial Z} p(Z, Y)\right)^{\mathrm{T}}-\alpha Y+v\right\rceil,(27)
$$

where $\alpha>0$ is a positive real constant and $v$ is an external signal which is connected to the reference input. The signal $v$ provides an alternative solution for adjusting the control of system to its non-zero equilibrium points. $v$ equals to zero if the equilibrium points are already considered.

According to Equation (27), the passive control function becomes

$u_{1}=-(\bar{y}-a) Y+\bar{x} Z_{1}-Z_{3}+d \bar{y} Z_{3}+d Z_{1} Z_{3}-\alpha Y+v$.

If the conversions $Z_{1}=e_{2}, Z_{2}=e_{3}, Z_{2}=e_{4}$, and $Y=e_{1}$ are taken back, the passive controller is rewritten as

$u_{1}=-(\bar{y}-a) e_{1}+\bar{x} e_{2}-e_{4}+d \bar{y} e_{4}+d e_{2} e_{4}-\alpha e_{1}+v$.

Hence, the control of hyperchaotic finance system (3) with uncertain parameters by using the passivity based feedback control method is provided with Equations (19) and (29).

\subsection{The Speed Feedback Control}

Yu et al. achieved the control of hyperchaotic finance system by means of a speed feedback controller [46]. The controlled hyperchaotic finance system is constructed by

$$
\begin{aligned}
& \dot{x}=z+(y-a) x+w, \\
& \dot{y}=1-b y-x^{2}, \\
& \dot{z}=-x-c z, \\
& \dot{w}=-d x y-k w-k_{2} \dot{x},
\end{aligned}
$$

where the control gain is calculated as $k_{2}=3.5$ for the $E_{1}$ equilibrium point [46].

\subsection{The Linear Feedback Control}

Yu et al. applied the control of hyperchaotic finance system using linear feedback controllers [46]. It is designed by

$$
\begin{aligned}
& \dot{x}=z+(y-a) x+w-k_{3}(x-\bar{x}), \\
& \dot{y}=1-b y-x^{2}-k_{3}(y-\bar{y}), \\
& \dot{z}=-x-c z, \\
& \dot{w}=-d x y-k w-k_{3}(z-\bar{z}),
\end{aligned}
$$

where the control gain is evaluated as $k_{3}=1.5$ for the $E_{2}$ equilibrium point [46]. 


\section{The Numerical Simulations}

In this section, computer simulations are performed to demonstrate the controlled hyperchaotic finance systems in Equations (3), (30), and (31). In all numerical simulations, the fourth-order Dormand-Prince method is used with variable-time step. MATLAB ${ }^{\circledR}$ software is used. The parameter values of hyperchaotic finance system are taken as $a=0.9, b=0.2, c=1.5$, $d=0.2$, and $k=0.17$ with the initial values $x(0)=1, y(0)$ $=2, z(0)=0.5$, and $w(0)=0.5$ to ensure the chaotic behaviour [46].

For obtaining the control to all equilibrium points, the coefficients of the speed feedback and linear feedback controllers are taken as $k_{2}=5.5$ and $k_{3}=3.5$, respectively. For providing the same conditions, the passive control parameters are taken as $\alpha=3.5, v=0$; and the linear feedback controller gain in the proposed control method is considered as $k_{1}=3.5$. The controllers are activated at $t=40$ for showing both the chaotic trajectories and the control in the simulations. The results for the speed feedback, linear feedback, and proposed passive feedback control of hyperchaotic finance system towards $E_{1}, E_{2}$, and $E_{3}$ equilibrium points are demonstrated comparatively in Fig. 4, Fig. 5, and Fig. 6, respectively.

As expected, the related Figs. 4-6 show that the outputs of hyperchaotic finance system converge to its equilibrium points after the controllers are activated. Hence, the computer simulations have confirmed all the theoretical analyses. Figs. 4-6 include comparative results for the control of hyperchaotic finance system. While control is provided at $t \geq 41.5$ by using the passive feedback controllers, it is observed when $t \geq 46.5$ with the linear feedback controllers and $t \geq$ 68 with the speed feedback controller for $E_{1}(0,5,0,0)$ equilibrium point. The signals $x$ and $z$ play significant role in the control performance of linear feedback controllers, and the signal $y$ plays significant role in the control performance of speed feedback controller. Furthermore, the control is firstly observed with the passive feedback controllers for both $E_{2}(1.66,-8.87$, $-1.11,17.4)$ and $E_{3}(-1.66,-8.87,1.11,-17.4)$ equilibrium points. The speed feedback control method provides the worst control performance again. The signal $z$ designates the effectiveness of linear feedback controllers in overall. To summarize, the comparisons show that the proposed control method, which combines

\section{Figure 4}

The controlled hyperchaotic finance system towards $E_{1}(0,5,0,0)$ equilibrium point when the controllers are activated at $t=40$ for (a) $x$, (b) $y$, (c) $z$, and (d) $w$ time series

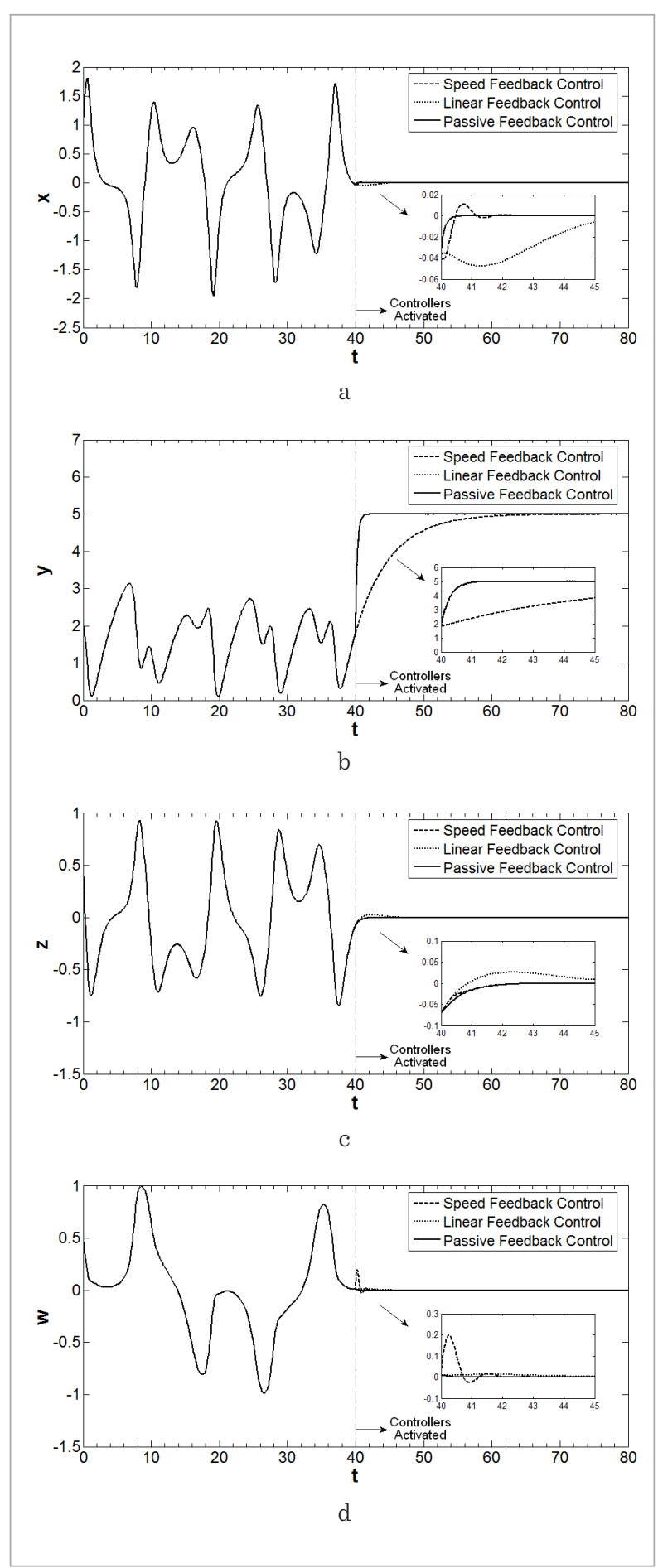




\section{Figure 5}

The controlled hyperchaotic finance system towards $E_{2}(1.66$, -8.87, -1.11, 17.4) equilibrium point when the controllers are activated at $t=40$ for (a) $x$, (b) $y$, (c) $z$, and (d) $w$ time series
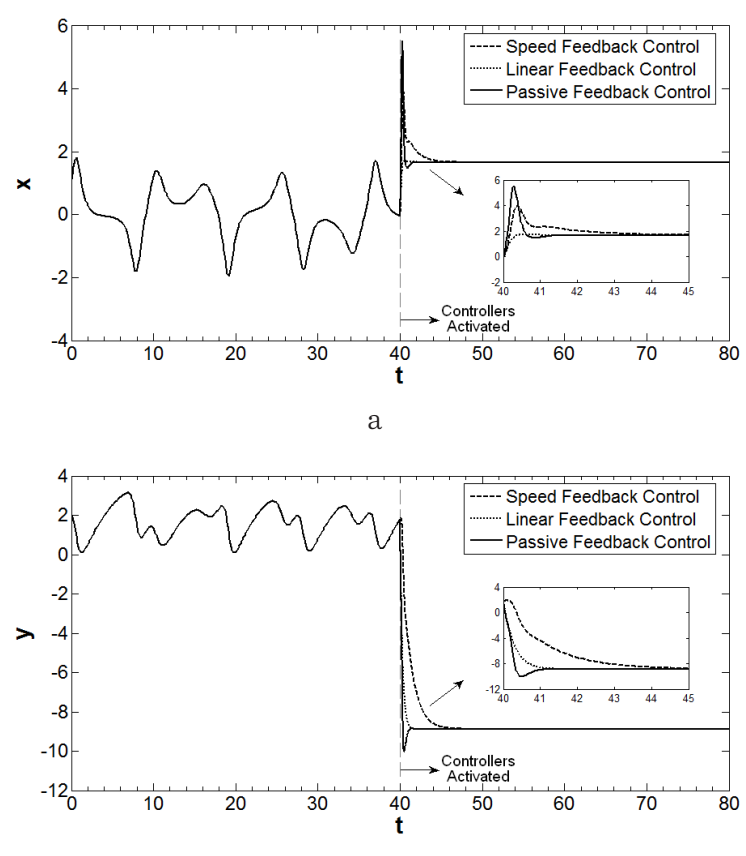

b
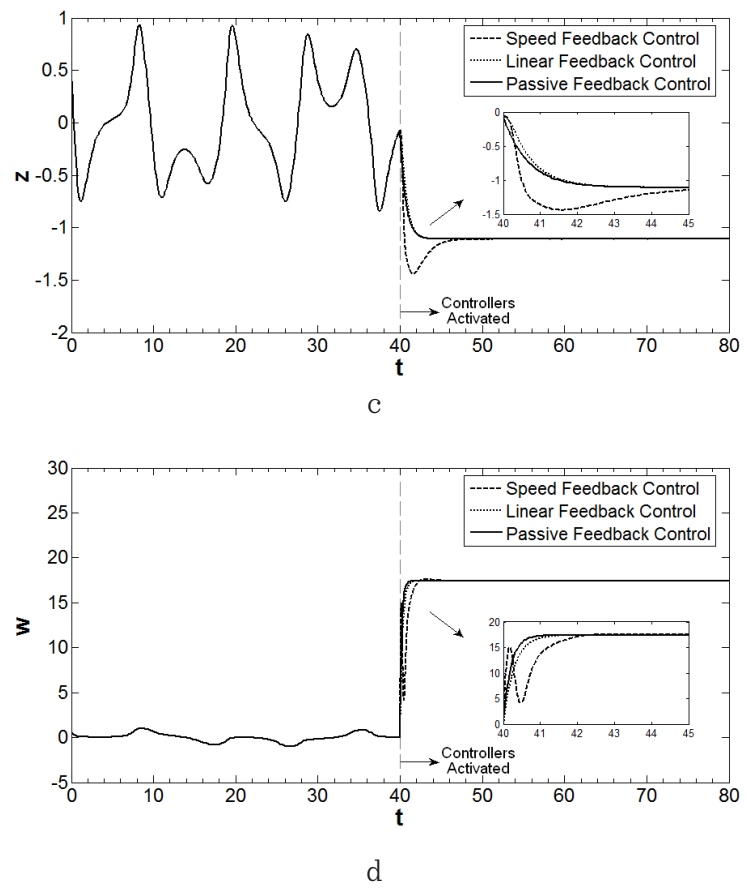

Figure 6

The controlled hyperchaotic finance system towards $E_{3}(-1.66$, $-8.87,1.11,-17.4$ ) equilibrium point when the controllers are activated at $t=40$ for (a) $x$, (b) $y$, (c) $z$, and (d) $w$ time series
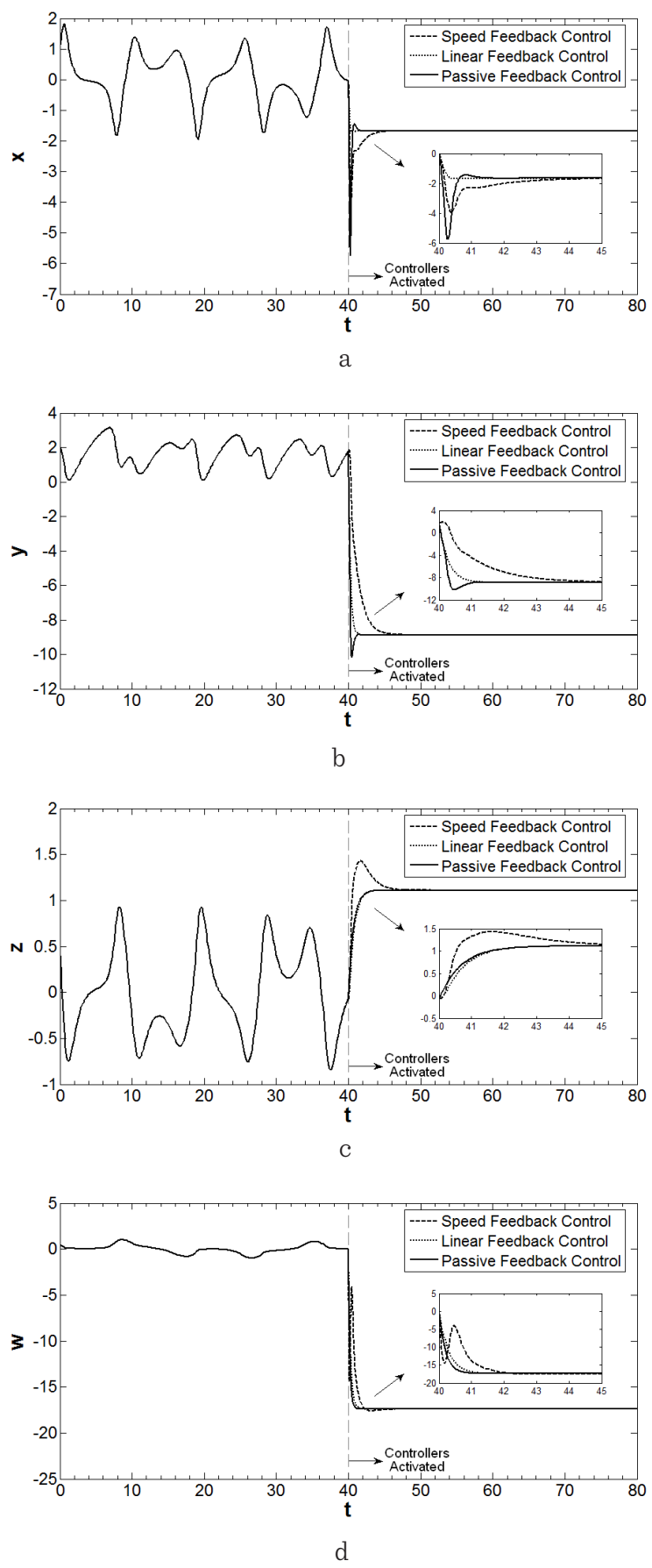
passive and feedback control methods, performs better than the speed feedback and linear feedback control methods for the control of the hyperchaotic finance system.

\section{Conclusions}

In this paper, the control of a hyperchaotic finance system is realized with a hybrid control approach. The finance systems are very sophisticated nonlinear systems that are interested in market and cover many unpredictable factors. The control of finance systems neutralizes many undesired factors in the economic systems and utilizes some benefits to regular growth. For this purpose, the passive control method is investigated for the control of a hyperchaotic finance system which was proposed by Yu et al. in 2012, but the classical passive control theory does not maintain its control.

\section{References}

1. Abd-Elouahab, M. S., Hamri, N. E., Wang, J. W. Chaos Control of a Fractional-Order Financial System. Mathematical Problems in Engineering, 2010, 2010, 270646. https://doi.org/10.1155/2010/270646

2. Azarfar, A., Shandiz, H. T., Shafiee, M. Adaptive Control for Nonlinear Singular Systems. Information Technology and Control, 2014, 43(2), 188-198. http://dx.doi. org/10.5755/j01.itc.43.2.4958. https://doi.org/10.5755/ j01.itc.43.2.4958

3. Cai, G. L., Huang, J. A New Finance Chaotic Attractor. International Journal of Nonlinear Science, 2007, 3(3), 213-220.

4. Cai, G. L., Yang, M. Z. Globally Exponentially Attractive Set and Synchronization of a Novel Three-Dimensional Chaotic Finance System. 3rd International Conference on Information and Computing, Wuxi, Jiangsu, China, June 4-6, 2010, 70-73. https://doi.org/10.1109/ICIC.2010.111

5. Cai, G. L., Yu, H. J., Li, Y. X. Stabilization of a Modified Chaotic Finance System. 4th International Conference on Information and Computing, Phuket Island, Thailand, April 25-27, 2011,188-191.https://doi.org/10.1109/ ICIC.2011.110

6. Chen, W. C. Dynamics and Control of a Financial System with Time-Delayed Feedbacks. Chaos, Solitons \& Frac-
As a solution, passivity based feedback controllers have been designed to achieve the asymptotic stability of the continuous time hyperchaotic finance system towards its equilibrium points. Numerical simulations have confirmed the theoretical analysis of the proposed passive feedback controllers in Equations (19) and (29). Simulation results also show that the proposed controllers regulate the hyperchaotic finance system to its equilibrium points faster than the speed feedback and linear feedback controllers. As a result, the proposed method is more appropriate for the control of new hyperchaotic finance system. Future researches may be applied on the control, synchronization, and stabilization of chaotic and hyperchaotic systems by using the proposed passive feedback control method.

\section{Acknowledgement}

We would like to present our thanks to anonymous reviewers for their helpful suggestions.

tals, 2008, 37(4), 1198-120\%. https://doi.org/10.1016/j. chaos.2006.10.016

7. Chen, M. Y., Han, Z. Z. Controlling and Synchronizing Chaotic Genesio System via Nonlinear Feedback Control. Chaos, Solitons \& Fractals, 2003, 17(4), 709-r16. https:/doi.org/10.1016/S0960-07r79(02)00487-3

8. Chen, X., Liu, C. Passive Control on a Unified Chaotic System. Nonlinear Analysis: Real World Applications, 2010, 11(2), 683-68\%. http://dx.doi.org/10.1016/j. nonrwa.2009.01.014. https://doi.org/10.1016/j.nonrwa.2009.01.014

9. Chen, Y., Yan, Z. Y. Chaos Control in a New Three-Dimensional Chaotic $\mathrm{T}$ System. Communications in Theoretical Physics, 2008, 49(4), 951-954. https://doi. org/10.1088/0253-6102/49/4/30

10. Ding, J., Yang, W., Yao, H. A New Modified Hyperchaotic Finance System and Its Control. International Journal of Nonlinear Science, 2009, 8(1), 59-66.

11. Emiroglu, S., Uyaroglu, Y., Koklukaya, E. Control of a Chaotic Finance System with Passive Control. 3rd International Symposium on Sustainable Development, Sarajevo, Bosnia and Herzegovina, May 31-June 1, 2012, 125-130.

12. Fang, Y. M., Yuan, Z. L., Fei, J. T. Adaptive Fuzzy Backstepping Control of MEMS Gyroscope Using Dynamic 
Sliding Mode Approach. Information Technology and Control, 2015, 44(4), 380-386. https://doi.org/10.5755/ j01.itc.44.4.9110

13. Gambino, G., Lombardo, M. C., Sammartino, M. Global Linear Feedback Control for the Generalized Lorenz System. Chaos, Solitons \& Fractals, 2006, 29(4), 829837. https://doi.org/10.1016/j.chaos.2005.08.072

14. Gelberi, H., Emiroglu, S., Uyaroglu, Y., Yalcin, M. A. Time Delay Feedback Control of Chaos in a Hyper Chaotic Finance System. 3rd International Symposium on Sustainable Development, Sarajevo, Bosnia and Herzegovina, May 31-June 1, 2012, 139-144.

15. Goksu, A., Kocamaz, U. E., Uyaroglu, Y. Synchronization and Control of Chaos in Supply Chain Management. Computers \& Industrial Engineering, 2015, 86(4), 107115. https://doi.org/10.1016/j.cie.2014.09.025

16. Hegazi, A., Agiza, H. N., El-Dessoky, M. M. Controlling Chaotic Behaviour for Spin Generator and Rossler Dynamical Systems with Feedback Control. Chaos, Solitons \& Fractals, 2001, 12(4), 631-658. https://doi. org/10.1016/S0960-0779(99)00192-7

17. Hu, P., Cai, G. L., Yao, L., Fang, X. L. Recursive Backstepping Nonlinear Control and Sliding Mode Control of a Novel Hyperchaotic Finance System. 2nd International Conference on Computer and Information Application, Taiyuan, China, December 8-9, 2012, 7777-780. https:// doi.org/10.2991/iccia.2012.187

18. Hwang, C. C., Hsieh, J. Y., Lin, R. S. A Linear Continuous Feedback Control of Chua's Circuit. Chaos, Solitons \& Fractals, 1997, 8(9), 1507-1515. https://doi.org/10.1016/ S0960-0779(96)00150-6

19. Kocamaz, U. E., Goksu, A., Taskin, H., Uyaroglu, Y. Synchronization of Chaos in Nonlinear Finance System by Means of Sliding Mode and Passive Control Methods: A Comparative Study. Information Technology and Control, 2015, 44(2), 172-181. https://doi.org/10.5755/j01. itc.44.2.7732

20. Kocamaz, U. E., Taskin, H., Uyaroglu, Y., Goksu, A. Control and Synchronization of Chaotic Supply Chains Using Intelligent Approaches. Computers \& Industrial Engineering, 2016, 102, 476-487. https://doi.org/10.1016/j. cie.2016.03.014

21. Kocamaz, U. E., Uyaroglu, Y., Cagil, G., Taskin, H., Cagil, Z. Control of Chaotic Finance System Using Artificial Neural Networks. Chaotic Modeling and Simulation, 2015, 2015(4), 289-302.

22. Kocamaz, U. E., Uyaroglu, Y., Kizmaz, H. Controlling Hyperchaotic Rabinovich System with Single State
Controllers: Comparison of Linear Feedback, Sliding Mode, and Passive Control Methods. Optik, 2017, 130, 914-921. https://doi.org/10.1016/j.ijleo.2016.11.006

23. Luo, J. H., Li, G. J., Liu, H. Linear Control of Fractional-Order Financial Chaotic Systems with Input Saturation. Discrete Dynamics in Nature and Society, 2014, 802429. https://doi.org/10.1155/2014/802429

24. Lü, J. H., Lu, J. N. Controlling Uncertain Lü System Using Linear Feedback. Chaos, Solitons \& Fractals, 2003, 17(1), 127-133. https://doi.org/10.1016/S09600779(02)00456-3

25. Ma, J. H., Chen, Y. S. Study for the Bifurcation Topological Structure and the Global Complicated Character of a Kind of Non-Linear Finance System (I). Applied Mathematics and Mechanics, 2001, 22(11), 1240-1251. https://doi.org/10.1023/A:1016313804297

26. Ma, J. H., Chen, Y. S. Study for the Bifurcation Topological Structure and the Global Complicated Character of a Kind of Non-Linear Finance System (II). Applied Mathematics and Mechanics, 2001, 22(11), 1375-1382. https://doi.org/10.1023/A:1022806003937

27. Mahmoud, E. E., Abualnaja, K. M. Comments on "Passive and Impulsive Synchronization of a New Four-Dimensional Chaotic System”. International Journal of Scientific \& Engineering Research, 2013, 4(11), 16181620.

28. Mahmoud, G. M., Mahmoud, E. E., Arafa, A. A. Passive Control of n-Dimensional Chaotic Complex Nonlinear Systems. Journal of Vibration and Control, 2013, 19(7), 1061-1071. https://doi.org/10.1177/1077546312439430

29. Ott, E., Grebogi, C., Yorke, J. A. Controlling Chaos. Physical Review Letters, 1990, 64(11), 1196-1199. https://doi. org/10.1103/PhysRevLett.64.1196

30. Pan, I., Das, S., Das, S. Multi-objective Active Control Policy Design for Commensurate and Incommensurate Fractional Order Chaotic Financial Systems. Applied Mathematical Modelling, 2015, 39(2), 500-514. https:// doi.org/10.1016/j.apm.2014.06.005

31. Pang, S. Q., Liu, Y. J. A New Hyperchaotic System from the Lü System and Its Control. Journal of Computational and Applied Mathematics, 2011, 235(8), 2775-2789. https://doi.org/10.1016/j.cam.2010.11.029

32. Peng, C. C., Chen, C. L. Robust Chaotic Control of Lorenz System by Backstepping Design. Chaos, Solitons \& Fractals, 2008, 37(2), 598-608. https://doi. org/10.1016/j.chaos.2006.09.057

33. Qi, D., Zhao, G., Song, Y. Passive Control of Chen Chaotic System. 5th World Congress on Intelligent Control and 
Automation, Hangzhou, China, June 15-19, 2004, 12841286. https://doi.org/10.1109/WCICA.2004.1340844

34. Shahverdiev, E. M. Controlling Chaos in Some Laser Systems via Variable Coupling and Feedback Time Delays. International Journal of Modern Physics B, 2016, 30(25), 1650181. https://doi.org/10.1142/ S0217979216501812

35. Tacha, O. I., Volos, C. K., Kyprianidis, I. M., Stouboulos, I. N., Vaidyanathan, S., Pham, V. T. Analysis, Adaptive Control and Circuit Simulation of a Novel Nonlinear Finance System. Applied Mathematics and Computation, 2016, 276, 200-217. https://doi.org/10.1016/j. amc.2015.12.015

36. Tao, C. H., Yang, C. D. Three Control Strategies for the Lorenz Chaotic System. Chaos, Solitons \& Fractals, 2008, 35(5), 1009-1014. https://doi.org/10.1016/j.chaos.2006.06.089

37. Tao, C. H., Yang, C. D., Luo, Y., Xiong, H. X., Hu, F. Speed Feedback Control of Chaotic System. Chaos, Solitons \& Fractals, 2005, 23(1), 259-263. https://doi.org/10.1016/j. chaos.2004.04.009

38. Uyaroglu, Y., Kocamaz, U. E., Goksu, A., Can, E. Sliding Mode Control of Hyperchaotic Finance System. 1st International Work-Conference on Time Series, Granada, Spain, June 25-27, 2014, 260-268.

39. Uyaroglu, Y., Temel, R., Kirlioglu. H. Feedback Control of Chaos in a Hyperchaotic Finance System. 3rd International Symposium on Sustainable Development, Sarajevo, Bosnia and Herzegovina, May 31-June 1, 2012, 135-138.

40. Vaidyanathan, S. A Novel 3-D Jerk Chaotic System with Three Quadratic Nonlinearities and Its Adaptive Control. Archives of Control Sciences, 2016, 26(1), 19-47. https://doi.org/10.1515/acsc-2016-0002

41. Wang, M. J., Wang, X. Y. Controlling Liu System with Different Methods. Modern Physics Letters B, 2009, 23(14), 1805-1818. https://doi.org/10.1142/ S0217984909019971

42. Yang, M. Z., Cai, G. L. Chaos Control of a Non-Linear
Finance System. Journal of Uncertain Systems, 2011, 5(4), 263-270.

43. Yang, J. H., Zhang, E. L., Liu, M. Bifurcation Analysis and Chaos Control in a Modified Finance System with Delayed Feedback. International Journal of Bifurcation and Chaos, 2016, 26(6), 1650105. https://doi. org/10.1142/S0218127416501054

44. Yassen, M. T. Controlling Chaos and Synchronization for New Chaotic System Using Linear Feedback Control. Chaos, Solitons \& Fractals, 2005, 26(3), 913-920. https://doi.org/10.1016/j.chaos.2005.01.047

45. Yu, W. Passive Equivalence of Chaos in Lorenz System. IEEE Transaction on Circuits and Systems-I: Fundamental Theory and Applications, 1999, 46(7), 876-878. https://doi.org/10.1109/81.7r74240

46. Yu, H. J., Cai, G. L., Li, Y. X. Dynamic Analysis and Control of a New Hyperchaotic Finance System. Nonlinear Dynamics, 2012, 67(3), 2171-2182. https://doi. org/10.1007/s11071-011-0137-9

47. Yu, J., Vincent, T. L. Investigation on Control of Chaos. Chinese Journal of Aeronautics, 1997, 10(3), 233-238.

48. Zhang, R. Y. Bifurcation Analysis for a Kind of Nonlinear Finance System with Delayed Feedback and Its Application to Control of Chaos. Journal of Applied Mathematics, 2012, 2012, 316390. https://doi. org/10.1155/2012/316390

49. Zhang, X. D., Liu, X. D., Zheng, Y., Liu, C. Chaotic Dynamic Behavior Analysis and Control for a Financial Risk System. Chinese Physics B, 2013, 22(3), 030509. https://doi.org/10.1088/1674-1056/22/3/030509

50. Zhao, M. C., Wang, J. W. H-Infinity Control of a Chaotic Finance System in the Presence of External Disturbance and Input Time-Delay. Applied Mathematics and Computation, 2014, 233, 320-327. https://doi. org/10.1016/j.amc.2013.12.085

51. Zhu, C. X., Chen, Z. G. Feedback Control Strategies for the Liu Chaotic System. Physics Letters A, 2008, 372(22), 4033-4036. https://doi.org/10.1016/j.physleta.2008.03.018 